\title{
A EDUCAÇÃO DE ADULTOS E JOVENS E ADULTOS: UM OLHAR SOBRE O PASSADO E O PRESENTE*
}

\author{
OSMAR FÁvERo, \\ da Universidade Federal Fluminense. \\ MARINAIDE FreITAS, \\ da Universidade Federal de Alagoas.
}

\begin{abstract}
Resumo: Este trabalho constitui-se em um grande desafio, considerando a abrangência da temática e o objetivo de debatermos e refletirmos sobre o passado histórico da Educação de Adultos (EDA) e da Educação de Jovens e Adultos (EJA), tendo em vista a necessidade de compreendermos o seu presente, diante da ausência de políticas educacionais voltadas para a área, em nosso país, que chega a 2011 sem superar o analfabetismo das pessoas acima de 15 anos. É um texto polifônico e ainda inacabado. Foi elaborado a quatro mãos, contendo olhares e vozes de pesquisadores da área, por isto caracterizamos como estudo exploratório, a partir de análises dos documentos pesquisados. Está estruturado em seis eixos temáticos que denominamos passos, temporalizados e nomeados a partir do foco de cada época mencionada.

Palavras-chave: Histórico da Educação de Adultos e da Educação de Jovens e Adultos. Educação supletiva. Educação Popular. Educação permanente. Educação continuada.
\end{abstract}

$1{ }^{\circ}$ PASSO: PAsCHOAL LeMME (1938-1940): EDUCAÇÃO SUPLETIVA/EDUCAÇÃO DE ADULTOS ${ }^{1}$

Historicamente foi o primeiro trabalho sobre educação de adultos no Brasil, apresentado como tese de concurso para técnico de educação do Ministério de Educação e Saúde (MES), em 1938, tomando como base as experiências realizadas pelos países desenvolvidos, a exemplo da

\footnotetext{
* Artigo recebido em 22/05/2011 e aprovado em 27/07/2011.
} 
Inglaterra, França, Estados Unidos, após o final da $1^{\text {a }}$ Grande Guerra Mundial (1914-1918). Época em que foram implantadas extensas redes de educação não sistemática, chamadas de extraescolar e em que foram recuperados os resultados das pesquisas realizadas na Psicologia sobre a capacidade dos adultos aprenderem, realizados por Thorndike. ${ }^{2}$ Retoma também os importantes estudos de Dewey ${ }^{3}$ e Kilpatrick, ${ }^{4}$ muito atuais na época.

Nesse estudo de Pascoal Lemme fica explícito que o termo educação popular refere-se à extensão do ensino elementar, na época escola primária (de 4 anos, considerada obrigatória somente até os 10 anos de idade), às crianças e aos adolescentes e adultos das camadas populares. Para os adultos, essa extensão reduzia-se, em geral, à alfabetização oferecida em cursos noturnos, de curta duração, que constituíam a forma mais elementar de solução da questão. Funcionavam incipientemente à míngua de recursos financeiros e, sobretudo, de atenção esclarecida dos seus responsáveis, o que ainda acontece no nosso país.

Lemme (2004, p. 49) afirma ainda que a revolução industrial gerou uma dupla exigência para a educação de adultos:

Nesta fase, vamos encontrar a educação de adultos com um duplo aspecto: de um lado, satisfazendo às necessidades das classes dirigentes e por elas estimulada; de outro, incluída entre as reivindicações das classes populares, cada vez mais ávidas de aperfeiçoarem suas condições culturais e técnicas.

No caso brasileiro, o pesquisador não considera as atividades educacionais desenvolvidas por empresas, desde os primórdios da implantação das primeiras indústrias no século XIX. Não comenta também as iniciativas desenvolvidas pelos anarquistas ${ }^{5}$ e outros grupos políticos, mas refere-se como importante a experiência do Liceu de Artes e Ofícios, criado em 1856, no Rio de Janeiro, que mantinha cursos noturnos para operários. Detém-se, em especial, na experiência dos Cursos de Extensão, Continuação, Aperfeiçoamento e Oportunidade, por ele concebidos, instalados e coordenados no antigo Distrito Federal (atualmente Município do Rio de Janeiro), em 1935, durante a gestão de Anísio Teixeira na Diretoria de Educação de Adultos e Difusão Cultural ${ }^{6}$ da Secretaria de Educação.

Merece destaque a qualidade excepcional desse estudo, pela atualidade de muitas afirmações feitas, em particular sobre as atitudes e competência dos professores para trabalhar na educação de adultos e pela coerência do compromisso político do autor com o atendimento prioritário aos operários e demais pessoas das classes populares. 


\section{PASSO: LOURENÇO FILHO (1945-1962) - O PROBLEMA DA EDUCAÇÃO DE ADULTOS $^{7}$}

Ao lermos os escritos de Lourenço Filho, a partir da temática acima mencionada, observamos que assume a definição de educação de adultos tendo por base a proposta por Moehlman (1944, p. 587, apud LOURENÇO FILHO, 1945, p. 176), ou seja: consistiria em qualquer plano, sistemático ou assistemático, de educação destinada a adolescentes e adultos, independente dos planos escolares convencionais, de instituições públicas e particulares.

Recorrendo à literatura estrangeira, afirma que a capacidade de aprender dos adultos requer uma metodologia especial de ensino que considere o desuso da aprendizagem, desenvolva a autoconfiança e parta do diálogo. Para tanto, deveriam ser disponibilizados o rádio, a imprensa, o cinema, a biblioteca, as discotecas, dentre outros meios.

Outra questão por ele enfocada, que permanece importante e discutida ainda hoje, é a formação de professores para atuar nas classes de jovens e adultos. Naquela época, ele enfatizava:

[...] todas as vezes que alguém que assuma a responsabilidade de educar necessitará de ordem e método, isto é, de compreensão segura dos fundamentos de seu trabalho. É o conhecimento do método que distingue o verdadeiro profissional do amador, mesmo quando este possua o título de professor. (LOURENÇO FILHO, 1945, p. 180)

E complementava:

Quem pretenda ensinar a adultos, como às crianças, precisará de conhecer, por pouco que seja, os processos de aprendizagem e os princípios gerais da didática. Mas estes ainda não bastam. Há na verdade, uma pedagogia especial para adultos. (LOURENÇO FILHO, 1945, p. 180)

Entendemos, ainda, que essa pedagogia especial implica o respeito às especificidades da modalidade, o respeito e o aproveitamento dos saberes dominados pelos jovens e adultos, e o respeito à heterogeneidade dos sujeitos que dela participam.

Lourenço Filho $(1945$, p. 177) indicava como funções da educação de adultos:

a) supletiva, de combate ao analfabetismo;

b) profissional, visando a reajustar o homem às novas condições de trabaIho, por meio de cursos extraescolares de continuação, aperfeiçoamento e difusão cultural; 
c) cívico-social, no caso de migrantes do país e imigrantes estrangeiros.

A função supletiva foi inteiramente assumida pela primeira Campanha de Educação de Adolescentes e Adultos (CEAA), organizada pelo Ministério da Educação e Saúde (MES), a partir de 1947. Os alunos analfabetos eram atendidos em classes de emergência, designadas como de ensino supletivo e organizadas com apoio das secretarias de educação e entidades privadas. As aulas eram noturnas, com professores do antigo ensino primário ou voluntários, e material didático produzido em grandes quantidades e distribuído pelo MES: cartilha de alfabetização Ler, livro de leitura Saber, elaborados segundo o método Laubach, ${ }^{8}$ e Manual de Aritmética, além de fascículos sobre higiene e saúde, civismo, técnicas agrícolas rudimentares, dentre outros pontos.

Influenciada pela criação da Organização das Nações Unidas para a Educação, a Ciência e a Cultura (Unesco), em 1947, a CEAA assume o amplo conceito de educação de base no sentido de:

1) desenvolvimento do pensamento e dos meios de relacionamento (ler e escrever, falar e ouvir, calcular); 2) desenvolvimento profissional (agricultura, trabalhos caseiros, edificação, formação técnica e comercial necessária ao progresso econômico); 3) desenvolvimento de habilidades domésticas (preparação de comida, cuidado das crianças e enfermos); 4) desenvolvimento de meios de expressão da própria personalidade em artes e ofícios; 5) desenvolvimento sanitário por meio da higiene pessoal e coletiva; 6) conhecimento e compreensão do ambiente físico e dos processos naturais (elementos científico-práticos); 7) conhecimento e compreensão do ambiente humano (organização econômica e social, leis e governos); 8) conhecimento das outras partes do mundo e dos povos que nelas habitam; 9) conhecimento de qualidades que capacitam o homem a viver no mundo moderno, como o são o ponto de vista pessoal e a iniciativa, o triunfo sobre o medo e a superstição, a simpatia e a compreensão para com as opiniões diferentes; 10) desenvolvimento moral e espiritual; fé nos ideais éticos e aquisição do hábito de proceder de acordo com eles, com a obrigação de submeter a exame as formas de condutas tradicionais e de modificá-las segundo o requeiram as novas circunstâncias. (Unesco, 1949, p. 11-12; trad. de BEISIEGEL, 1974, p. $81-82 ; 2004$, p. 91-92)

Esta Campanha coincidiu com o movimento de expansão da escola primária para crianças, inaugurando o apoio do MES aos estados e destes aos municípios no atendimento escolar obrigatório. Demarca a institucionalização de educação de adultos, uma vez que teve a União como sua implementadora, 
contando com recursos financeiros do Fundo Nacional do Ensino Primário (FNEP).

Compreendemos como institucionalização da EDA e da EJA as ações, desde a alfabetização ao ensino médio, realizadas historicamente, tendo por base o aparato das leis/normas/resoluções advindas das esferas nacional, estaduais e municipais, bem como outros documentos referenciais internacionalmente constituídos. ${ }^{9}$

Em uma análise mais geral, podemos afirmar, com Mészaros (2005), que a educação, especialmente nos últimos 150 anos, serviu - no seu todo ao propósito de não só fornecer os conhecimentos e o pessoal necessário à máquina produtiva em expansão do sistema do capital, como também gerar e transmitir um quadro de valores que legitima os interesses dominantes, como se não pudesse haver nenhuma alternativa à gestão da sociedade, seja na forma internalizada, pelos indivíduos devidamente educados e aceitos, seja por meio de uma dominação estrutural e uma subordinação hierárquica implacavelmente imposta.

Retomando o histórico brasileiro, a CEAA, por influência da proposta de desenvolvimento de comunidades divulgada pelos Estados Unidos e da experiência das missões rurais realizadas no México, foi reforçada, a partir de 1950, pela Campanha Nacional de Educação Rural (CNER), que também partia do conceito de educação de base, estrategicamente designada como educação rural, adentrando também na categoria de iniciativas institucionalizadas no Brasil. ${ }^{10}$

Nesse mesmo período, o governo federal incentivou ainda a criação, em 1946, do Serviço Nacional de Aprendizagem Industrial (Senai) e logo depois do Serviço Nacional de Aprendizagem Comercial (Senac), vinculados ao Ministério do Trabalho, Indústria e Comércio, visando à formação profissional com a colaboração dos setores industrial e comercial. ${ }^{11}$

\section{PASSO: MOVIMENTOS DE CULTURA E EDUCAÇÃO POPULAR DO INÍCIO DA DÉCADA DE 1960}

O amadurecimento do processo democrático, revelado nas eleições majoritárias de 1958; as experiências inovadoras na área da cultura e os debates sobre educação, na segunda metade dos anos de 1950; a promulgação da primeira Lei de Diretrizes e Bases da Educação Nacional, em 1961; e a aprovação do Plano Nacional de Educação, em 1962; ao lado do enfraquecimento das campanhas nacionais, criaram as condições para novas experiências de educação de adultos, com a consequente redefinição 
de um conceito de alfabetização voltado apenas para ler, escrever e contar. Por isso, pode ser caracterizado como um momento de ruptura com a forma institucionalizada até então, viabilizando o repensar da Educação de Adultos no Brasil.

O primeiro sinal é dado pelo discurso do Presidente da República, Juscelino Kubitschek de Oliveira, na abertura do II Congresso Nacional de Educação de Adultos realizado no Rio de Janeiro, em 1958, sobre o importante papel da educação dos adultos na solução dos problemas criados pelo desenvolvimento econômico.

Cabe, assim, à educação dos adolescentes e adultos, não somente suprir, na medida do possível, as deficiências da rede de ensino primário, mas também e muito principalmente dar um preparo intensivo, imediato e prático aos que, ao se iniciarem na vida, se encontram desarmados dos instrumentos fundamentais que a sociedade moderna exige para completa integração nos seus quadros: a capacidade de ler e escrever, a iniciação profissional técnica, bem como a compreensão dos valores espirituais, políticos e morais da cultura brasileira. Vivemos, realmente, um momento de profundas transformações econômicas e sociais na vida do País. A fisionomia das áreas geográficas transforma-se contínua e rapidamente, com o aparecimento de novas condições de trabalho que exigem, cada vez mais, mão-de-obra qualificada e semiqualificada. O elemento humano convenientemente preparado, que necessita nossa expansão industrial, comercial e agrícola, tem sido e continua a ser um dos pontos fracos da mobilização de força e recursos para o desenvolvimento. Essa expansão vem sendo tão rápida e a consequente demanda de pessoal tecnicamente habilitado tão intensa, que não podemos esperar a sua formação regular de ensino; é preciso uma ação rápida, intensiva, ampla e de resultados práticos e imediatos, a fim de atendermos os reclamos do crescimento e do desenvolvimento da Nação. (KUBITSCHEK DE OLIVEIRA, 1958, p. 3)

É também nesse congresso que pela primeira vez é questionada a prioridade dada à educação, e em especial à alfabetização, como motora do pretendido desenvolvimento econômico-social. No relatório de uma das comissões do seminário preparatório realizado em Pernambuco, cujo relator foi Paulo Freire, afirma-se que o problema fundamental é a miséria do povo e propõe-se outra forma de trabalho educativo: não sobre ou para o homem, mas com ele, considerando"imperativa sua participação em todos os momentos do trabalho educativo, preparatória ou concomitante àquela outra ainda mais estimável, que é a participação na vida da região e nas esferas mais amplas da sociedade em que vive". ${ }^{2}$ 
Na efervescência no contexto histórico da realidade brasileira, foi realizada a implantação de vários movimentos designados de cultura popular, entre os quais destacam-se: Movimento de Cultura Popular (MCP, Recife, 1960); Centro Popular de Cultura da União Nacional dos Estudantes (UNE, 1961), que se expandiu para vários estados; Campanha De Pé no Chão se Aprende a Ler (Natal, 1961); Campanha de Educação Popular da Paraíba (CEPLAR, 1962); Movimento de Educação de Base (MEB), criado pela Conferência Nacional dos Bispos do Brasil (CNBB), em 1961, com apoio do governo federal; e o Sistema de Alfabetização Paulo Freire, que, a partir da experiência de Angicos, em 1963, inovou radicalmente não só o conceito de alfabetização como consolidou o próprio modo de trabalhar com os adultos.

A fundamentação apresentada e a proposta do sistema de alfabetização de adultos sugerida por Paulo Freire, nessa ocasião, configura-se em um novo entendimento da educação de adultos, cujo passo inicial seria a alfabetização feita na perspectiva da conscientização (FREIRE, 1963). Não temos dúvida em afirmar que a melhor metodologia de trabalho foi o Sistema Paulo Freire de Alfabetização, que estava na base de um amplo Sistema de Educação de Adultos, iniciado com a alfabetização e culminando com uma Universidade Popular, numa perspectiva de alargamento da continuidade dos estudos bem mais avançada do que a que encontramos nos dias atuais.

De acordo com o foco deste texto, o importante a destacar do conjunto dos movimentos de cultura e educação popular do início dos anos de 1960 é:

a) o conceito de cultura popular, assumido como fundamental, do qual passou a derivar o conceito de educação popular - não a disseminação da cultura erudita aos setores populares, mas a consideração da cultura do povo como expressão de sua visão de mundo e, a partir dela, no que se designou conscientização, pensar a transformação da realidade em uma perspectiva democrática;

b) uma nova forma, consequentemente, de entender a alfabetização, proposta por Paulo Freire, com expressa dimensão política; e

c) a definição e vinculação assumida dos movimentos de cultura e educação popular com o movimento social mais amplo, no qual teve origem e ao qual se alia na luta por um novo projeto histórico.

A melhor expressão desse compromisso encontra-se em um documento denominado Plano de Ação do MCP para 1963:

1. Um movimento de cultura popular só surge quando o balanço das relações de poder começa a ser favorável aos setores populares da comunidade 
e desfavorável aos seus setores de elite. Esta nova situação caracteriza, de modo genérico, o quadro atual da vida brasileira [...].

2. O movimento popular gera o movimento de cultura popular. O movimento popular, ao atingir determinada etapa de seu processo de desenvolvimento, experimenta a necessidade de liquidar certos entraves de ordem cultural que se apresentam como barreiras características daquela etapa, dificultando a passagem para a etapa seguinte. A superação de tais dificuldades se apresenta como condição para o prosseguimento do processo.

3. O movimento popular não gera um movimento cultural qualquer. Gera, precisamente, um movimento de cultura popular. Os interesses culturais do movimento popular têm, portanto, um caráter específico: exprimem a necessidade de uma produção cultural, a um só tempo voltada para as massas e destinada a elevar o nível de consciência social das forças que integram, ou podem vir a integrar, o movimento popular.

4. A demanda por uma consciência popular adequada ao real e possuída pelo projeto de transformá-lo é característica do movimento popular porque este se assenta nas três seguintes pressuposições: a) só o povo pode resolver os problemas populares; b) tais problemas se apresentam como uma totalidade de efeitos que só pode ser corrigida pela supressão de suas causas, radicadas nas estruturas sociais vigentes; $c$ ) o instrumento que efetua a transformação projetada é a luta política guiada por ideias que representam adequadamente a realidade objetiva. ${ }^{13}$

O MEB, o único movimento que atuava exclusivamente no meio rural, que havia iniciado seus trabalhos de alfabetização por meio de escolas radiofônicas e assumido, em um primeiro momento, o conceito de educação de base da Unesco, redefiniu-o radicalmente ao final de 1962:

Considerando as dimensões totais do homem, entende-se como educação de base o processo de autoconscientização das massas, para uma valorização plena do homem e uma consciência crítica da realidade. Esta educação deverá partir das necessidades e dos meios populares de participação, integrados em uma autêntica cultura popular, que leve a uma ação transformadora. Concomitantemente, deve propiciar todos os elementos necessários para capacitar cada homem a participar do desenvolvimento integral de suas comunidades e de todo o povo brasileiro. ${ }^{14}$

Num segundo momento houve redefinições, com o amadurecimento do trabalho junto às comunidades rurais e alternativas à censura aos programas radiofônicos; o MEB passou a privilegiar o contato direto com a população atingida. Nesse movimento, redefiniu o desgastado conceito de desenvolvimento de comunidades, criando o de animação popular, entendida como um processo essencialmente político, porque 
a) é uma educação de vida comunitária, de participação comum nos problemas e soluções de cada dia e, por isso, é um processo gradativo de conscientização;

b) estrutura a comunidade de tal forma que possibilita a participação política de cada um na vida da comunidade, através de grupos e trabalhos comuns;

c) leva inevitavelmente a ampliar esta vida política para o processo político nacional. (MEB, 1966, p. 27)

Em termos da definição da educação de adultos, ainda neste período, há um registro importante que merece ser feito: o Seminário promovido pela Superintendência de Desenvolvimento do Nordeste (Sudene) e realizado em Recife, em janeiro de 1967, com o propósito de fixar as diretrizes para os programas de educação de adultos na Região Nordeste. Mesmo considerando o momento político autoritário que o Brasil vivia, foi elaborado com muita clareza e pertinência o Documento Final das Diretrizes, contendo propostas para um Programa da Educação de Adultos da Superintendência para o Desenvolvimento do Nordeste (BRASIL, 1967). Essas propostas, exemplificadas a seguir, foram abortadas:

a) a educação de adultos não pode se limitar a "alfabetizar por alfabetizar", mas deve preparar os indivíduos e os grupos para participarem responsável e produtivamente de um processo de mudança cultural identificado como um processo de desenvolvimento socioeconômico. (p. 2)

b) Quando a educação de adultos é repensada em termos de desenvolvimento, é indispensável que se leve em conta a grande massa de marginalizados. É necessário que esta parte da população seja motivada para que, de modo consciente, integre, participe e assuma o processo de mudança, uma vez que este mundo adulto é detentor de capacidade de decisão, de esforço, de trabalho e pensamento não solicitados na medida de suas possibilidades. (p. 10)

c) Em termos da realidade brasileira, a educação de adultos, integrada em um conjunto de medidas, deve ter como consequência, entre outras, libertar o homem da condição de "objeto" dos processos culturais. (p. 10)

Os movimentos de educação popular, surgidos no mesmo período, dão um salto qualitativo em relação às campanhas e mobilizações governamentais contra o analfabetismo de adultos, ou de educação rural, dos anos de 1940 e 1950. Foram iniciativas qualitativamente diferentes das ações anteriores. Havia um compromisso explicitamente assumido em favor das classes populares, urbanas e rurais, assim como orientação da ação educativa para uma ação política. 
Em nosso entender, perdeu-se, nesse período, a oportunidade significativa de absorver as práticas de educação popular como política pública. A alfabetização e educação das pessoas adultas, no início dos anos de 1960, apareciam como perigosas para a estabilidade do regime e para a preservação da ordem capitalista e por isto foram suprimidas pelo golpe militar de 1964.

$4^{\circ}$ PASSO: EDUCAÇÃO PERMANENTE, EDUCAÇÃO CONTINUADA (FINAL DOS ANOS DE 1960 E INÍCIO DOS ANOS DE 1970)

De um lado, as exigências postas pelas transformações no sistema produtivo e a grande demanda pela expansão do ensino em níveis cada vez mais elevados produziram, na Europa, o que se designou como crise da educação (COOMBS, 1968). De outro lado, o relativo fracasso das grandes campanhas de alfabetização e o insucesso do planejamento educacional nos países considerados subdesenvolvidos passaram a enfatizar os modos de educação não escolares, ou realizados à margem dos sistemas de ensino regulares, que passaram a ser designados como não formais ou extraescolares.

O tema da educação permanente privilegiava a educação de adultos, referida, em primeiro plano, pelo menos no caso europeu, à possibilidade de formação para o mercado de trabalho, necessariamente continuada, exigida pelos novos sistemas de produção. Alguns autores abordavam também, e algumas vezes prioritariamente, a formação cultural mais ampla, propondo aprendizagens sistemáticas ou livres no lazer ou nas férias, por meio do cinema, da literatura, do turismo, dentre outras formas de aprender.

Essa foi a perspectiva mais desenvolvida teoricamente, no Brasil e na América Latina. Mas as críticas feitas às experiências europeias, sobretudo francesas, denunciavam que as atividades consideradas de educação permanente ou de educação continuada eram promovidas, sobretudo, por empresas e sempre postas em termos de atualização profissional.

A produção sobre estes temas foi bastante grande e divulgada pela Unesco e pela Organização de Cooperação para o Desenvolvimento Econômico (OCDE). No entanto, a produção de autores brasileiros foi muito limitada. Quem garantiu a divulgação desses conceitos no país, de forma significativa, foi Pierre Furter, ${ }^{15}$ por meio da publicação de vários livros, bastante lidos entre nós. Por sua vez, o n. 113 da Revista Brasileira de Estudos Pedagógicos, de jan./mar. 1969, contém importante dossier sobre o tema, inclusive o documento de trabalho "Educação permanente na perspectiva do desenvolvimento nacional", elaborado por Pierre Furter e Aníbal Buitrón para o simpósio realizado em Caracas em 1968, sintetizando as discussões e 
as propostas existentes, assim como propondo alternativas para a América Latina.

É também desse período a publicação do relatório coletivo da Comissão Internacional para o Desenvolvimento da Educação, criada pela Unesco, Aprender a ser, coordenada por Edgar Faure, ${ }^{16}$ em 1972, que se tornou um catecismo para os defensores da educação permanente. Menos divulgado, mas também importante e bastante mais concreto - desde a explicitação do sistema de valores que orientava o projeto, reorganização das escolas, valorização de outras agências educativas, até a proposta de organização de distritos educativos - é o relatório "A educação amanhã: um projeto de educação permanente", produzido pela Fundação Europeia da Cultura, sob coordenação de Bertrand Schwartz. ${ }^{17}$

Em termos teóricos, a concepção de educação permanente partia da incompletude do homem, a ser completada com o apoio de processos educativos durante toda a vida e não apenas na faixa etária privilegiada para a educação básica, compreendida pelo início da escolarização até o ensino médio, realizados em várias instituições da sociedade e não apenas em escolas. Na sistematização proposta por Furter (1966, p. 136) afirma-se:

[...] a educação permanente não pode ser reduzida nem a uma educação "extraescolar", nem "complementar", nem "prolongada", nem "fundamental", nem tampouco"de adultos", porque todas estas interpretações só veem uma parte do problema. A educação permanente não é algo que se acrescente a um sistema dado. Não é um novo setor, um novo campo. É uma nova perspectiva que leva os educadores a redefinir toda e qualquer educação.

Um de seus pontos fundamentais era a relação entre a educação geral e a educação técnica ou a formação profissional, especialmente sua relação intrínseca: sem educação geral de qualidade não se consegue uma formação profissional satisfatória, em termos de abstração e capacidade de decisão exigidas pelos novos processos produtivos.

No caso brasileiro, os anos de 1970 até meados dos anos de 1980 foram marcados por duas ações complementares, embora pouco articuladas: a Lei $n .5692 / 71$, que criou os ensinos de $1^{\circ}$ e $2^{\circ}$ Graus e sistematizou o Ensino Supletivo, em termos de exames e cursos, e o Movimento Brasileiro de Alfabetização (Mobral), ambas influenciadas pela ideologia da educação permanente.

No primeiro caso, o Parecer n. 699/72 do Conselho Federal de Educação justificou a criação de um Sistema de Ensino Supletivo, paralelo ao Sistema de Ensino Regular, prevendo a criação de outro modelo de escola os Centros de Ensino Supletivo (CES), existentes ainda em alguns estados - e 
tentando coordenar e certificar, pelo menos em parte, ações já realizadas pelo Senai e Senac, por exemplo. No mesmo movimento, o MEC implantou vários projetos visando a regularizar a situação de profissionais experientes, mas não titulados, sobretudo em nível médio: desenhistas, enfermeiros, professores, dentre outras categorias, com base em regulamentação própria e materiais didáticos específicos.

Quanto aos exames supletivos, a partir da criação do $1^{\circ} \mathrm{Grau}$, reunindo o antigo primário e o curso ginasial, o mercado de trabalho passou a exigir o certificado de oito anos de estudos. A procura da certificação neste nível mobilizava milhares de pessoas, que lotavam estádios de futebol, obrigando a padronização dos exames em nível nacional. Embora com menor intensidade, a procura dos exames supletivos de $2^{\circ} \mathrm{Grau}$, naquele período, também foi significativa, tendo se tornado crescente no período mais recente, quando o mercado de trabalho passou a exigir a certificação em nível do ensino médio. ${ }^{18}$

O conceito de educação de adultos assumido pelo Departamento de Ensino Supletivo (DSU) do MEC é, em primeiro lugar, de suplência do ensino não obtido no sistema regular, e de suprimento, entendido como complementação da educação recebida nos bancos escolares, a ser obtida em outras agências de formação. Embora se justifique pela categoria de educação permanente, sua proposta é estritamente escolar, prevendo para os adultos repetidas voltas à escola - o que é uma evidente redução do conceito.

Deve-se anotar, neste período, a presença de adolescentes e jovens nos cursos de ensino supletivo, em parte porque expulsos do ensino regular por terem superado a idade dos 14 anos, prevista como limite para a obrigatoriedade do $1^{\circ} \mathrm{Grau}$, hoje do Ensino Fundamental, cunhando-se a expressão juvenilização do supletivo. Mas também porque muitos jovens migravam para as metrópoles, em busca de trabalho nas grandes obras de infraestrutura: pontes, elevados, metrô etc. As próprias discussões sobre a educação permanente começam a incorporar a categoria juventude, recuperada como temática importante pela Sociologia. ${ }^{19}$

O Mobral tem sua história bastante conhecida, embora a produção sobre ele seja pequena. Estruturou-se como fundação, com poderosa coordenação nacional e comissões coordenadoras em praticamente todos os municípios. Com integral apoio dos governos militares e recebendo transferências vultosas da Loteria Esportiva e doações do empresariado, deduzidas do Imposto de Renda por elas devido, foi a campanha de alfabetização mais ampla e mais rica, o que lhe permitiu produzir farto material didático, centralizado em plano nacional, e importantes investimentos na formação de pessoal. 
No entanto, o exame do material didático utilizado tanto para a alfabetização quanto para as classes ditas de ensino integrado, constituemse, na verdade, uma reposição da primeira fase do ensino de $1^{\circ} \mathrm{Grau}$, revelando a adoção das mesmas sistemáticas utilizadas nas escolas regulares. Sua concepção de educação permanente é a adotada pelos economistas da educação, justificando a necessidade de mais estudo para melhor desempenho nas tarefas profissionais, cada vez mais exigentes pela transformação dos meios de produção.

Segundo Ribeiro (1992) esse movimento teve também um indicador de população bastante jovem. A pesquisadora, aproximando-se dos diversos estudos apresentados à época, constatou que algo em torno de $60 \%$ dos estudantes do Mobral tinham menos de 20 anos e mais da metade deles já havia frequentado a escola. Sua demanda, pois, não era majoritariamente de adultos, que não tiveram acesso à escola na infância, ou que passaram muitos anos dela afastados.

É importante deixar registrado também que, tanto nas campanhas iniciadas nos anos de 1940 quanto nos movimentos do início dos anos de 1960, foi produzido e distribuído farto material sobre higiene, saúde e trabalhos a serem feitos com poucos recursos. No caso do Mobral, no entanto, sua produção mais interessante, sobre temas culturais e de divulgação de obras clássicas, parece não ter chegado aos alunos.

\section{PASSO: Constituinte de 1987-1988; Constituição FEderal de 1988 E ANOS DE 1990}

A intensa participação das organizações e movimentos na Constituinte gerou uma postura muito ativa e a produção de vários documentos em defesa da educação básica de 12 anos - compreendendo a educação infantil, o ensino fundamental, o ensino médio e a educação de jovens e adultos - e propostas específicas para cada uma dessas modalidades. A conquista maior, expressa na Constituição de 1988, foi a declaração do ensino fundamental como direito público subjetivo. Seu não oferecimento, ou sua oferta irregular, importa responsabilidade da autoridade competente - inclusive para os que não tiveram oportunidade de cursá-lo ou concluí-lo na idade própria.

A partir de então, com o retorno das eleições diretas para prefeitos, os municípios que foram administrados por partidos políticos progressistas buscaram qualificar a EJA, institucionalizando-a no contexto de suas secretarias de educação, criando setores/departamentos responsáveis pela sua implantação, cuidando da formação continuada de professores, 
elaborando propostas curriculares específicas, muitas delas retomando as propostas freirianas, dentre outros pontos. Os municípios brasileiros que mais se destacaram à época foram Porto Alegre, Santos, São Paulo, Diadema dentre outros.

Registramos, como iniciativa de governos locais, o Movimento de Alfabetização (Mova) ${ }^{20}$ surgido na cidade de São Paulo no governo Luíza Erundina, na gestão de Paulo Freire como secretário municipal de educação (1989-1991).

Esse movimento nasceu com uma nova configuração que procurava envolver o poder público e a sociedade civil, com o objetivo de combater o analfabetismo, oferecendo o acesso à educação de forma a atender às necessidades e condições dos alunos jovens e adultos e à continuidade dos estudos por meio dos sistemas estaduais e municipais de ensino. Com significativa atuação no Sul e no Sudeste do país, não conseguiu espaço no Ministério de Educação para transformar sua prática em política pública para EJA, em 2003, nem mesmo quando da ascensão ao poder de um presidente da República do Partido dos Trabalhadores, tendo sido preterido pelo Programa Brasil Alfabetizado (PBA). Sobrevive ainda em alguns estados e municípios brasileiros, embora descaracterizado, contando com recursos do governo federal destinados ao PBA.

De acordo com Jane Paiva (2004) muitas são as iniciativas de EJA que, em certas condições e com diferentes graus de controle, fazem institucionalmente a parceria sociedade civil-Estado, existindo municipalidades realmente sensíveis à demanda pela EJA que têm dado respostas positivas para seu atendimento. Essas experiências são de grande importância, porque vêm construindo saberes, lideranças e legitimidade política.

Quanto à educação dos trabalhadores, durante as discussões da Constituinte de 1987, as primeiras propostas, inscritas no capítulo dos direitos dos trabalhadores, previam sua liberação para a realização de atividades educativas no próprio local de trabalho ou em instituições próximas. Elas foram recusadas, no final da primeira fase nas discussões, pelo rolo compressor da bancada conservadora do Congresso Nacional, apoiada por forças de direita.

Por sua vez, as decisões inscritas no art. 60 das Disposições Transitórias da Constituição previam a ação intensiva no sentido de eliminar o analfabetismo em dez anos. Esta decisão foi abortada pelo governo Fernando Henrique Cardoso que, em sintonia com as diretrizes dos organismos internacionais, passou a privilegiar a universalização do ensino fundamental para crianças, embora desenvolvendo outra campanha de alfabetização de adultos, em 
bases já superadas: o Programa Alfabetização Solidária (PAS) ${ }^{21}$ - denominada a partir de 2003 de Alfasol -, implantada por intermédio da organização não governamental Comunidade Solidária.

Paradoxalmente, apesar do contexto social apontar para um novo direcionamento à EJA, retoma-se a proposta de campanhas, envolvendo os vários segmentos da sociedade, inclusive o empresariado, e fazendo parcerias com entidades não governamentais que assumem a tarefa a baixo custo, de alfabetização das pessoas jovens e adultas.

No período, foi importante ainda a discussão posta por algumas entidades e por alguns educadores sobre a categoria "trabalho" como fundamental, tanto para a educação em geral, em especial para o ensino médio, quanto para a educação de jovens e adultos em particular. A palavrachave era politecnia que, segundo Saviani (2003, p. 140):

[...] diz respeito ao domínio dos fundamentos científicos das diferentes técnicas que caracterizam o processo de trabalho produtivo moderno. Está relacionada aos fundamentos das diferentes modalidades de trabalho e tem como base determinados princípios, determinados fundamentos que devem ser garantidos pela formação politécnica.

A ideia de politecnia envolve a articulação entre trabalho intelectual e trabalho manual, implicando uma formação que, a partir do próprio trabalho social, desenvolva a compreensão das bases da organização do trabalho da nossa sociedade e que, portanto, nos permite compreender o seu funcionamento.

A história recente é bastante conhecida e é suficiente destacar nela, no período imediatamente seguinte, em primeiro lugar, a produção do relatório da Comissão Internacional do Século XXI, em 1996, conhecido como Relatório Delors (presidente da comissão). Trabalhando a elaboração das diretrizes da educação para o Século XXI, atualizou o conceito de educação ao longo da vida. Esse conceito, no Relatório, é visto como uma das chaves para o século XXI.

O referido Relatório, publicado no Brasil em 1998, com o apoio do MEC e apresentação de Paulo Renato, ministro de educação à época, ${ }^{22}$ propõe quatro pilares sobre os quais deveria assentar-se a educação de adultos:

a) aprender a conhecer - não apenas a aquisição de um repertório de saberes codificados, mas o domínio dos próprios instrumentos do conhecimento, considerado como meio e finalidade da vida;

b) aprender a fazer - indissociável do aprender a conhecer, liga-se à formação profissional, substituindo o conceito de qualificação profissional pelo de competência pessoal; 
c) aprender a viver juntos - opondo a esperança à violência e tentando superar o potencial de destruição criado durante o século XX;

d) aprender a ser - ou seja, contemplar o desenvolvimento integral da pessoa, para que possa decidir por si mesma, de forma crítica, nas diferentes circunstâncias da vida.

Mais ainda que o Relatório Faure, de 1972, que atualiza em parte, o Relatório Delors é visto e criticado como expressão do momento atual do capitalismo e da globalização da economia. Suas propostas são em geral divulgadas quando não assumidas como dogmas, sem contextualizar sua produção, nem procurar referi-la a outras realidades distintas dos países considerados desenvolvidos.

Duarte (2000) observa que, aparentemente, o Relatório Delors trabalha com um raciocínio calcado na busca de equilíbrio e conciliação entre polos opostos, sendo capaz de superar as visões unilaterais acerca da educação. Numa leitura rápida e superficial, pode-se considerá-lo um documento dialético. No entanto, na avaliação do pesquisador, o relatório em foco, nada tem a ver com qualquer tipo de dialética; apresenta-se como:

[...] um mero recurso discursivo de tentar manter-se na metade do caminho entre posições opostas e decorrendo de insuperáveis limitações da própria ótica da comissão. Não são, porém limitações de caráter unicamente lógicoepistemológicas, mas principalmente limitações de natureza ideológica [...], que impedem de avançar na direção da crítica ao capitalismo gerador de conflitos (não só de tensões), conflitos esses que não podem encontrar solução efetiva sem a superação da sociedade capitalista. (DUARTE, 2000, p. 48-49)

Muito mais importante, no período, foi a realização da $V$ Conferência Internacional de Educação de Adultos (V Confintea), realizada em Hamburgo, na Alemanha, em 1998, ${ }^{23}$ inclusive e talvez principalmente pelas reuniões nacionais e regionais preparatórias.

A contribuição latino-americana foi importante. Foi a região que insistiu na necessidade de considerar prioritário o trabalho educativo com jovens carentes e de conceder ao problema de gênero valor especial; seus representantes exigiram a necessidade de superar a educação centrada em desempenhos; passar de uma educação controlada em exames a outra, baseada na responsabilidade individual e coletiva; de educação acumuladora de informações para uma educação que processe e utilize essa informação. (RIVERO, 2000, p. 112) 
Foi a partir desse momento que se consagra a expressão Educação de Jovens e Adultos, e que foi criado, na Anped, o GT 18 de Educação de Pessoas Jovens e Adultas. No caso brasileiro, a preparação da V Confintea, foi praticamente liderada por profissionais que trabalham em entidades que praticavam ou se interessavam pela educação de jovens e adultos. $\mathrm{O}$ documento final, produzido em vários encontros com ampla participação, foi rejeitado pelo Ministério da Educação, pois sua política era, como foi dito, de um lado, priorizar a universalização do ensino fundamental e, de outro, realizar uma campanha de alfabetização nos moldes já superados e à margem do próprio Ministério da Educação, a Alfabetização Solidária.

Por influência de organizações da sociedade civil, afirma-se, nesse período, a defesa do direito de acesso dos jovens e adultos ao ensino fundamental e ao ensino médio, em cursos definidos conforme o estabelecido no art. n. 208, inciso VI, da Constituição Federal de 1988, reiterado pelo Inciso VI, do art. 4º das Diretrizes e Bases da Educação Nacional (Lei n. 9394/1996):

[...] oferta de educação escolar regular para jovens e adultos, com características e modalidades adequadas às suas necessidades e disponibilidades, garantindo-se aos que forem trabalhadores as condições de acesso e permanência escolar.

E, na defesa deste direito, organizam-se, primeiramente no Rio de Janeiro em 1998, depois progressivamente em todos os estados e em vários municípios, os Fóruns de Educação de Jovens e Adultos. Para Paiva (2009, p. 89) o ponto de partida desses fóruns foram as estratégias definidas na conferência regional preparatória à V Confintea, realizada em Brasília, em 1997:

a) centrar o foco da EJA no ensino e na aprendizagem, melhorando a qualidade do processo educativos;

b) atenção especial aos jovens;

c) vínculos com a transformação produtiva e com o trabalho;

d) superação do círculo vicioso da pobreza e ampliação de políticas de manejo sustentável do meio ambiente, no marco de um desenvolvimento justo;

e) práticas orientadas para desenvolver valores democráticos e os direitos humanos;

f) universalidade do direito à educação por toda a vida e adoção de perspectiva de aprendizagem permanente como expressão do desenvolvimento humano.

Da V Confintea realizada em Hamburgo, na Alemanha, dois documentos foram publicados e ganharam o mundo: a Declaração de Hamburgo 
e a Agenda para o Futuro, este último formulado a partir de dez temas de estudos, para os quais a Conferência indicou compromissos entre os estadosmembros. Por sua vez, a Declaração, dentre outros pontos, destaca os direitos à educação e o de aprender ao longo da vida, assim expressos:

O reconhecimento do "Direito a Educação" e o "Direito a Aprender por Toda a Vida" é mais que nunca uma necessidade: é o direito de ler e escrever; de questionar e analisar; de ter acesso a recursos e de desenvolver e praticar habilidades e competências individuais e coletivas. (Unesco, 1997, p. 93)

Ambos os documentos foram considerados no Brasil como referências para a modalidade e tiveram significativa repercussão entre os pesquisadores.

60 Passo: Os anos de 2000, Parecer Cury e situação atual

Quanto à legislação relativa à educação de jovens e adultos, há pelo menos três registros relativos a documentos oficiais importantes a serem feitos no período: o parecer CNE/CEB 11/2000, de autoria de Carlos Roberto Jamil Cury, relativo às Diretrizes Operacionais para a Educação de Jovens e Adultos; a Emenda Constitucional n. 53, de 19 de dezembro de 2006, que instituiu o Fundo de Manutenção e Desenvolvimento da Educação Básica e Valorização dos Profissionais da Educação (Fundeb), substituindo o Fundo de Manutenção e Desenvolvimento do Ensino Fundamental e de Valorização dos Profissionais da Educação (Fundef); e o Parecer CNE/CEB 03/2010, que reformulou as Diretrizes Operacionais para a Educação de Jovens e Adultos nos aspectos relativos à duração dos cursos e idade mínima para ingresso nos cursos, idade mínima e certificação nos exames e a educação de jovens e adultos desenvolvida por meio da educação à distância - decisão que provocou muitos debates entre os pesquisadores.

Em termos teórico-conceituais, o que mais nos interessa neste trabalho, é apenas o primeiro parecer. Além de reiterar o direito à educação para os jovens e adultos, supera o antigo conceito de ensino supletivo e avança na definição das funções dessa modalidade, estabelecendo:

a) função reparadora, que devolve a escolarização não conseguida quando criança;

b) função equalizadora, que cuida de pensar politicamente a necessidade de oferta maior para quem é mais desigual do ponto de vista da escolarização; e 
c) função qualificadora, entendida como o verdadeiro sentido da EJA, por possibilitar o aprender por toda vida, em processos de educação continuada. (PAIVA, 2009, p. 205)

No entanto, os termos da resolução derivada desse parecer ainda estão circunscritos à tradição do antigo ensino supletivo, tomando os parâmetros escolares como norteadores dos exames de certificação. $\mathrm{Na}$ mesma tradição, tanto o veto imposto ao FUNDEF, impedindo a aplicação de recursos na EJA, assim como a transferência da organização dessa modalidade aos municípios, provocou a transformação de antigas classes de ensino supletivo em ensino regular noturno, sem maiores adequações.

As próprias estatísticas relativas à EJA a tomam como sinônimo de ensino supletivo. São poucas as experiências de renovação efetiva desta modalidade, nas quais se pode localizar não só a influência da pedagogia de Paulo Freire, como do legado da educação popular, traduzida em alguns indicadores que representam rupturas com o antigo ensino supletivo e a rígida sistemática do ensino regular:

a) matrícula ao longo do ano;

b) mapeamento do perfil dos alunos visando ao agrupamento dos mesmos;

c) frequência flexível, em lugar dos termos evasão e abandono a introdução do conceito de interrupção;

d) momentos de encontro dos professores, em reuniões para planejar, rever a prática e planejar novamente;

e) novos espaços e novos projetos dentro e fora da escola;

f) avaliação flexível com momentos variados, consistindo em diagnóstico no início e avaliação qualitativa processual durante o período letivo, valendo-se de diversos recursos e instrumentos. ${ }^{24}$

No ano de 2003, com a assunção de um presidente da República oriundo da camada popular, contrariando as expectativas dos estudiosos da EJA e dos Fóruns de EJA, o MEC institucionalizou o Programa Brasil Alfabetizado (PBA). Direcionado para os estados, o Distrito Federal e os municípios com elevados índices de analfabetismo de jovens acima de 15 anos, este Programa, desde sua implantação inicial já passou por vários redesenhos e prolonga-se até os dias atuais,

O PBA visava e visa estimular ações supletivas e redistributivas, para a correção progressiva das disparidades de acesso e garantia de padrão de qualidade da alfabetização de jovens e adultos, com a implantação de programa 
específico de erradicação do analfabetismo em todo território nacional. Por meio da transferência de recursos financeiros advindos do Fundo Nacional de Desenvolvimento da Educação (FNDE), em caráter suplementar, aos entes federados que aderiram ao Programa e por meio do pagamento de bolsas benefício a voluntários (Resolução FNDE/CD, 2003).

Rummert e Ventura (2007) reconhecem que o governo Lula trouxe para a EJA maior destaque do que os governos anteriores da Nova República. Entretanto, o discurso que anunciou sua valorização, não se fez acompanhar de ações concretas para a superação da matriz construída na década anterior. Assim, embora o arco das ações no âmbito da EJA seja ampliado, permanece centrado nas políticas focais, fragmentadas e fragmentadoras do tecido social. As autoras referem-se implicitamente, nesse comentário, ao Programa Nacional de Inclusão de Jovens (Projovem) e ao Programa Nacional de Integração da Educação Profissional com a Educação Básica na Modalidade de Educação de Jovens e Adultos (Proeja).

Embora não envolvendo aspectos teórico-conceituais, retomamos o aspecto legal, para fazermos pelo menos uma observação sobre o Parecer CNE/CBE n. 03/2010. Homologado em 3 de junho de 2010, após dois anos de discussões, com discordâncias entre os participantes dos Fóruns de EJA e adiamento em sua homologação pelo ministro da educação, estabelece a idade mínima de 15 anos para ingresso na EJA, em nível do ensino fundamental, e de 18 anos, para o ensino médio.

O problema fundamental diz respeito à transferência obrigatória, na verdade à "expulsão" dos alunos do ensino fundamental com mais de 14 anos para as classes de EJA, o que vem ocorrendo desde a promulgação da Lei n. 5692/71. Nos municípios nos quais tem sido adotado sistematicamente, este procedimento normativo tem ocasionado problemas na organização da EJA. Concebida inicialmente como educação de adultos - designação que perdura até hoje nos eventos internacionais - está sendo obrigada a atender um contingente de jovens para os quais as propostas pedagógicas adotadas mostram-se inadequadas. Ao mesmo tempo, parece que, se não com a mesma intensidade do afluxo de jovens, a EJA passou a ser demandada também por pessoas idosas e portadoras de necessidades especiais, que merecem atendimentos diferenciados. Associando-se a isto há a crescente oferta de cursos à distância, que em pouco ou nada atualizam os cursos supletivos, e abre-se um amplo leque de problemas a serem enfrentados, de modo inovador, pelas instâncias responsáveis pela EJA.

Deve-se acrescentar, no período, a realização de duas importantes reuniões, ambas intensamente precedidas de reuniões regionais preparató- 
rias: a VI Confintea, realizada em Belém do Pará, em dezembro de 2009, e a Conferência Nacional de Educação (Conae), realizada em Brasília, em março de 2010, com o intento de fixar as bases para o futuro Plano Nacional de Educação. No caso da democratização do acesso, da permanência e do sucesso escolar, no caso da EJA, essas bases incluem:

A consolidação de uma política de educação de jovens e adultos, concretizada na garantia de formação integral, de alfabetização e das demais etapas de escolarização, ao longo da vida, inclusive aqueles/as em situação de privação de liberdade. Essa política - pautada pela inclusão e qualidade social - prevê um processo de gestão e financiamento que assegure isonomia de condições da EJA em relação às demais etapas e modalidades da educação básica, bem como a implantação do sistema integrado de monitoramento e avaliação, além de uma política de formação permanente específica para o/a professor/a que atue nessa modalidade de ensino e maior alocação do percentual de recursos para estados e municípios. Ainda, essa modalidade de ensino deve ser ministrada por professores/as licenciados/as. (BRASIL, 2010, p. 70)

Em termos de concepções de EJA, no entanto, as resoluções não vão além das estratégias de ação:

1) Promover a educação inclusiva pautada nos direitos humanos e no reconhecimento da diversidade, assim como o princípio do direito de aprender, ampliando conhecimentos ao longo da vida e não apenas escolarizando.

2) Estimular a concepção de projetos que contemplem a pedagogia da alternância, segundo a necessidade dos educandos/as.

3) Promover educação não sexista que combata a homofobia e todas as formas de discriminação e preconceito. (BRASIL, 2010, p. 152)

Essas resoluções incorporam parte do excelente relatório brasileiro preparatório à VI Confintea, apresentando como ponto de partida um diagnóstico atual da situação da educação de jovens e adultos. Ele relaciona inclusive os programas que traduzem as políticas dos diversos ministérios, analisa detalhadamente os desafios postos para a modalidade, e apresenta extensa relação de recomendações para as diversas instâncias.

Ainda em termos de concepções, vale transcrever alguns parágrafos desse relatório:

Primeiramente, cabe abordar a concepção ampliada de educação de jovens e adultos, que entende educação pública e gratuita como direito universal de aprender, de ampliar e partilhar conhecimentos e saberes acumulados ao longo da vida, e não apenas de se escolarizar. Em outras palavras, os 
educandos passam a maior parte de suas vidas na condição de aprendizes e, portanto, muitas são as situações de aprendizado que vivenciam em seus percursos formativos.

A consciência do direito à educação e a mobilização em sua defesa crescem entre a população jovem e adulta excluída do e no sistema escolar e fazem com que suas demandas sejam consideradas na conformação de projetos político-pedagógicos e de políticas públicas a ela destinadas. Quem são esses sujeitos? Como se expressam no mundo? Onde estão no território brasileiro? O que fazem? Como produzem a existência? Quais são seus desejos e expectativas? Que projetos de vida manifestam? Como aprendem? Esses sujeitos participam da elaboração das políticas públicas?

Pensar sujeitos da EJA é trabalhar para, com e na diversidade. A diversidade é constituída das diferenças que distinguem os sujeitos uns dos outros mulheres, homens, crianças, adolescentes, jovens, adultos, idosos, pessoas com necessidades especiais, indígenas, afro-descendentes, descendentes de portugueses e de outros europeus, de asiáticos, de latino-americanos, entre outros. (BRASIL, 2009, p. 27-28)

Esse modo de entender a EJA pode ser assumido como plataforma para rever os programas em execução, visando a reorientá-los na perspectiva de uma política integrada para jovens e adultos, assim como para redirecionar as práticas escolares tradicionais ainda prevalecentes nos sistemas de ensino. Pode e deve incorporar também, como preocupação específica, o atendimento aos jovens de 15 a 18 anos, em classes diurnas do sistema regular de ensino devidamente adequadas, assim como considerar os jovens e adultos atendidos e a serem atendidos pela EJA como trabalhadores, donos de experiências e de saberes acumulados ao longo da vida.

Retomamos especificamente a VI Confintea, que, por meio do Marco de Belém (2009), permanece enfatizando, a exemplo da V Confintea, a necessidade da educação ao longo da vida, expressão advinda do contexto dos eventos internacionais realizados por agências supranacionais como o Banco Mundial e a Unesco, a partir dos anos de 1990. Nesse sentido, é importante a crítica de Rummert e Alves (2010, p. 516):

[...] A aprendizagem ao longo da vida trata a nova fase capitalista de forma naturalizada e evoca a adaptação/preparação dos indivíduos como forma de responder ao novo quadro hegemônico internacional. Trata-se, assim, de promover a adaptação funcional dos sujeitos e da educação à economia, difundindo a crença de que os problemas de inserção ou permanência no mercado de trabalho são decorrentes da pouca ou inadequada formação dos trabalhadores. Essa perspectiva é justificada pela necessidade de maior 
qualificação para lidar com o mundo do trabalho, imposta pela dita complexa sociedade da informação ou sociedade do conhecimento.

Na realidade essa colocação merece nossa especial atenção no aprofundamento da questão. Em nome de um discurso defensor do universalismo da educação básica para os jovens e adultos com baixa escolarização, materializam-se políticas de governo fragmentárias e de baixa institucionalização, a exemplo do Projovem e do Proeja - embora ambos possuam, potencialmente, possibilidades de constituírem avanços significativos no âmbito teórico-metodológico da educação de jovens e adultos -, assim como do Enceja e do Certif, que, na verdade, conferem o direito não à educação, mas à certificação de escolaridade.

\section{ADULT AND YOUTH AND ADULT EDUCATION: A LOOK AT THE PAST AND PRESENT}

ABSTRACT: This study presents a great challenge, when one considers the breadth of its theme. It sets out to discuss and reflect on the past history of Adult Education and Youth and Adult Education, with a view to understanding its present. It does so against the background of our country's lack of educational policies for this area on reaching 2011 without eliminating the illiteracy of over 15-year-olds. It is a polyphonic and as yet unfinished text, prepared by four people with the views and voices of researchers in the field. Hence, it is characterized as an exploratory study, based on an analysis of the documents researched. It is built around six thematic areas called steps, situated in time and named according to the focus of each period mentioned.

KEYwORDS: History of Adult Education. History of Youth and Adult Education. Supplementary Education. Popular Education. Permanent Education. Ongoing Education.

\section{NOTAS}

1. Publicada inicialmente, como artigo, no Boletim do Ministério do Trabalho, Indústria e Comércio, em 1939, editada em 1940 pelo Jornal do Commercio, de Rodrigues e Cia, do Rio de Janeiro, e republicada em Paschoal Lemme (2004, p. 41-88).

2. Edward Lee Thorndike e seus colaboradores, em estudos comparativos realizados entre a capacidade de aprendizagem na infância, na adolescência e idades mais avançadas, segundo Lourenço Filho (1945, p. 11), comprovaram por meio de experiências que a infância não se apresentou como a melhor idade para aprender. Afirmaram à época que a melhor idade para aprendizagem é a dos 20 aos 30 anos; e qualquer idade entre 30 e 45 é ainda melhor do que as que medeiem entre 10 e 14.

3. Filósofo e pedagogo, reconhecido como um dos fundadores da escola filosófica de Pragmatismo (juntamente com Charles Sanders Peirce e William James); conside- 
rado um pioneiro em Psicologia Funcional e representante principal do movimento da educação progressiva norte-americana durante a primeira metade do século XX. Fundou uma escola conhecida como Escola de Educação ou Escola Dewey, na qual pôs em prática suas teorias pedagógicas.

4. Pedagogo, discípulo de Dewey. Defendia que não basta só a criança dar atenção àquilo que faz, é necessário também a intenção, pois esta torna o educando agente.

5. Brandão (2008) caracteriza as escolas anarquistas de e para trabalhadores entre aquelas que devem ser consideradas como uma alternativa de projeto cultural, por meio da educação popular, ou que pelo menos se aproximou dela.

6. Responsável pelo desenvolvimento dos serviços de ensino, de extensão e aperfeiçoamento, administração e direção artística dos teatros da municipalidade, os museus e bibliotecas públicas e escolares, bem como todas as organizações de natureza cultural ou educativa destinadas a adultos (cf. Parecer $2^{\circ}$ do Decreto n. 17 de 1935).

7. Palestra realizada a convite do Centro de Professores Noturnos do Rio de Janeiro, publicada na Revista Brasileira de Estudos Pedagógicos. v. 5, n. 14, ago. 1945, p. 169-185.

8. Criado nas Filipinas, em 1915, pelo missionário protestante norte-americano Frank Charles Laubach e depois utilizado em toda a Ásia e em vários países da América Latina. Laubach esteve no Brasil em 1943, tendo assessorado a equipe do Ministério da Educação e Saúde responsável pela elaboração do material didático da Campanha de Educação de Adolescentes e Adultos.

9. Por exemplo, a Declaração de Hamburgo (1997) e o Marco de Belém (2009).

10. Ver documentos da CEAA e da CNER em www.forumeja.org.br/edupopular/ campanhas.

11. Para maior aprofundamento ver Cunha (1975).

12. Relatório Final do Seminário Regional de Educação de Adultos de Pernambuco, preparatório ao II Congresso Nacional de Educação de Adultos, 1958, p. 8.

13. Reproduzido em Fávero (1983, p. 90-91) e em I Encontro Nacional de Alfabetização e Cultura Popular (MEC/Unesco, 2009, p. 60-61); disponível em www.forumeja.org. $\mathrm{br} /$ edupopular/mcp.

14. Reproduzido em Fávero (2006, p. 80).

15. Pierre Furter é um educador suíço que conheceu as experiências de Paulo Freire, no Nordeste, e foi durante vários anos perito da Unesco para a educação, no Brasil e na Venezuela, depois professor na Universidade de Neuchâtel, na Suíça. Seus livros diretamente ligados ao tema, publicados no Brasil, são: Educação e reflexão (Vozes, 1966); Educação e vida; uma contribuição à educação permanente (Vozes, 1966) e Educação permanente e desenvolvimento cultural (Vozes, 1974), no qual aborda diretamente o problema do analfabetismo e da educação de adultos. 
16. Edição portuguesa da Livraria Bertrand (Portugal) e Difusão Europeia do Livro (São Paulo), de 1974.

\section{Edição brasileira da Editora Vozes, de 1976.}

18. As melhores análises da política de ensino supletivo estão contidas na dissertação de mestrado de Sônia Maria De Vargas, A atuação do Departamento de Ensino Supletivo do MEC no período 1973-1979 (PUC-Rio, 1984) e na tese de Sérgio Haddad, Estado e educação de adultos, 1964-1985 (USP, 1991). Sobre os exames supletivos de $2^{\circ} \mathrm{Grau}$ dispõe-se do relato da pesquisa realizada no município do Rio de Janeiro, sob a coordenação de Cláudio Moura Castro: O enigma do supletivo (Edições UFC, 1980).

19. Significativa, nesse período, a criação do Programa de Educação de Jovens (PEJ), no município do Rio de Janeiro, quando Leonel Brizola era governador e Darcy Ribeiro vice-governador e secretário de educação do estado. Foi, provavelmente, o primeiro programa de uma secretaria de educação que procura recriar a proposta pedagógica de Paulo Freire. Ver Haddad (2007, p. 77-110).

20. A palavra movimento utilizada para caracterizar o Mova, semanticamente, é bem diferente da referência feita ao Mobral. O Mova atua como um movimento da sociedade civil em parceria permanente com os estados e municípios, com acentuada preocupação na continuidade dos estudos dos seus egressos.

21. Lançado na cidade de Natal, estado do Rio Grande do Norte, em setembro de 1996, no Dia Internacional da Alfabetização, quando se realizava um encontro nacional de jovens e adultos, preparatório para a V Conferência Internacional de Educação de Adultos (V Confintea). Sugere-se a leitura das investigações de Marinaide Lima Freitas, Letramento: as marcas de oralidade nas produções escritas de alunos jovens e adultos, Tese (Doutorado) - Programa de Pós-Graduação em Letras e Linguística. Universidade Federal de Alagoas, Maceió, 2002; Márcia Soares Alvarenga, Os sentidos da cidadania: entre vozes, silenciamentos e resistências no Programa Alfabetização Solidária. Tese (Doutorado) Programa de Pós-Graduação em Serviço Social. Universidade Federal do Rio de Janeiro, 2003; Clarice Traversini, Programa Alfabetização Solidária: o governamento de todos e de cada um. (Tese) Programa de Pós-Graduação em Educação da Universidade Federal do Rio de Janeiro, 2003.

22. Para Duarte (2000), esse apoio não seria dado, no caso de o documento vir a constituir-se em obstáculo para os reais objetivos do processo no qual se encontrava empenhado à época o MEC, processo esse caracterizado pelo então ministro da educação como um repensar da educação brasileira. $O$ discurso sobre educação era pautado pela importante tarefa de esconder as contradições do projeto neoliberal de sociedade.

23. O histórico dessa preparação e desta Conferência é detalhado criticamente no livro de Paiva (2009).

24. Síntese de consultas do autor. 


\section{REFERÊNCIAS}

BEISIEGEL, Celso de Rui. Estado e educação popular. 1. ed. São Paulo: Pioneira, 1974; 2. ed. Brasília: Liber Livro, 2004.

BRANDÃO, Carlos Rodrigues. A educação popular e a educação de adultos: antes e agora. In: MACHADO, Maria Margarida (Org.). Formação de educadores de jovens e adultos. Brasília: MEC/Secad; Unesco, 2008.

BRASIL. Conselho Federal de Educação. Parecer 699/72. Brasília. Revista Brasileira de Estudos Pedagógicos v.59, n. 131, p. 371-409, jul./set. 1973. (Publicado como artigo, sob o título Ensino Supletivo, de Walnir Chagas, autor do referido parecer).

. Constituição do Brasil, promulgada em 5 de outubro de 1988 e atualizada até a Emenda Constitucional n. 20, de 15/12/1998. 21. ed. São Paulo: Saraiva, 1999.

. Resolução FNDE/CD n. 18, de 10 de julho de 2003.

. Lei n. 5.692, de 11 de agosto de 1971. Fixa diretrizes e bases para o ensino de

$1^{\circ}$ e $2^{\circ}$ grau, e dá outras providências. Diário Oficial da União, Brasília, 12 ago. 1971.

. Lei n. 9394, de 20 de dezembro de 1996. Fixa as diretrizes bases da educação nacional. Brasília: MEC, 1996.

. Ministério do Interior, Superintendência para o Desenvolvimento do Nordeste Diretrizes para os programas de educação de adultos. Documento final do / Seminário de Educação e Desenvolvimento - Educação de Adultos. Recife: SUDENE - Divisão de Documentação, 1967.

. Ministério da Educação. Conselho Nacional de Educação. Câmara de Educação Básica. Parecer n. 11/2000. Diretrizes nacionais curriculares para a educação de jovens e adultos. Reproduzido em SOARES, Leôncio. Educação de Jovens e Adultos. Rio de Janeiro: DP\&A, 2002, p. 25-133.

. Secretaria de Educação Continuada, Alfabetização e Diversidade. Documento Base Nacional Preparatório a VI Confintea. Brasília, set. 2008.

. Documento Nacional Preparatório à VI Conferência internacional de Educação de Adultos (VI Confintea). Brasília: MEC, Goiânia: Funape/UFG, 2009.

CONAE 2010 - Conferência Nacional de Educação. Documento Final.

Brasília: MEC, 2010.

COOMBS, Philip H. The world educational crisis. New York: Oxford University Press, 1968.

DELORS, Jacques (Org.). Um tesouro a descobrir; relatório da Comissão Internacional sobre Educação para o século XXI. São Paulo: Cortez, 1999.

CUNHA, Luis Antonio. Educação e desenvolvimento social no Brasil. Rio de Janeiro: Francisco Alves, 1975.

DUARTE, Newton. Vigotski e o aprender a aprender: crítica às apropriações neoliberais e pós-modernas da teoria vigotskiana. Campinas: Autores Associados, 2000. 
FAVERO, Osmar. Cultura popular e educação popular: memória dos anos 60 . Rio de Janeiro: Graal, 1. ed. 1983; 2. ed. 2001.

Uma pedagogia da participação popular; análise da prática educativa do MEB Movimento de Educação de Base (1961-1966). Campinas: Autores Associados, 2006.

FAURE, Edgar et al. Aprender a ser. Lisboa: Livraria Bertrand, São Paulo: Difusão Europeia do Livro, 1974.

FREIRE, Paulo. Conscientização e alfabetização: uma nova visão do processo. Estudos Universitários: Revista de Cultura da Universidade do Recife, n. 4, abr./jun. 1963, p. 5-23.

FURTER, Pierre. Educação e vida. Petrópolis: Vozes, 1966.

HADDAD, Sérgio (Coord.). Novos caminhos em educação de jovens e adultos; um estudo de ações do poder público em cidades de regiões metropolitanas brasileiras. São Paulo: Ação Educativa \& Fapesp, 2007.

KUBITSCHEK DE OLIVEIRA, Juscelino. Discurso na abertura do II Congresso Nacional de Educação de Adultos. Associação Brasileira de Educação. Revista Educação, n. 61, 1958, p. 3.

LEMME, Paschoal. Educação supletiva/Educação de adultos. In: Paschoal Lemme. Memórias de um educador. v. 5: Estudos, educação e destaques da correspondência, Brasília: INEP, 1. ed. 2000, 2. ed., 2004, p. 41-88.

LOURENÇO Filho, M. B. O problema da educação de adultos. Revista Brasileira de Estudos Pedagógicos, v. 5, n. 14, agosto de 1945, p. 169-175.

MÉSZAROS, István. A educação: para além do capital. São Paulo: Boitempo, 2005.

MOVIMENTO DE EDUCAÇÃO DE BASE. Animação popular. Rio de Janeiro: MEB, 1966. Apostila 5. Disponível em www.forumeja.org.br/educpopular/meb. Acesso em 10 mar. 2011.

PAIVA, Jane. Educação de jovens e adultos: questões atuais em cenário de mudanças. In: OLIVEIRA, Inês Barbosa de; PAIVA, Jane (Orgs.). Educação de jovens e adultos. Rio de Janeiro: DP\&A, 2004.

Os sentidos do direito à educação para jovens e adultos. Petrópolis: DP\&A, Rio de Janeiro: FAPERJ, 2009.

RIVERO, José Herrera. Educação e exclusão na América Latina: reformas em tempo de globalização. Brasília: Universa, 2000.

RIBEIRO, Vera Masagão et al. Metodologia da alfabetização: pesquisas em educação de jovens e adultos. Campinas: Papirus/Cedi, 1992.

RUMMERT, Sonia Maria; VENTURA, Jaqueline Pereira. Políticas públicas para a educação de jovens e adultos no Brasil: a permanente (re)construção da subalternidade; considerações sobre os Programas Brasil Alfabetizado e Fazendo Escola. Educação em Revista n. 29, Curitiba, 2007. 
RUMMERT, Sonia Maria; ALVES, Natália. Jovens e adultos trabalhadores pouco escolarizados no Brasil e em Portugal: alvos da mesma lógica de conformidade. Revista Brasileira de Educação, v. 15 n. 45, p. 511-528, set./dez. 2010.

SAVIANI, Dermeval. O choque teórico da politecnia. Trabalho, Educação e Saúde, v. 1, n. 1, p. 140 e142, mar. 2003.

UNESCO. V Conferência Internacional de Educação de Jovens e Adultos. Hamburgo/ Alemanha. 1997.

Declaração de Hamburgo e Agenda para o Futuro - V Confintea. Hamburgo (Alemanha), 1997.

VI Conferência Internacional de Educação de Adultos. Marco de Ação de Belém, 4 de dezembro de 2009.

Osmar Fávero: Professor do Programa de Pós-Graduação em Educação da Universidade Federal Fluminense (UFF).

Email: ofavero@infolink.com.br

Marinaide Freitas: Professora do Curso de Pedagogia e da Pós-Graduação em Educação Brasileira da Universidade Federal de Alagoas (UFAL).

Email: naide12@hotmail.com 